ORIGINAL ARTICLE

\title{
Body Mass Index and Migraine: A Hospital-Based Study in Lahore
}

\author{
SHAHID MUKHTAR ${ }^{1}$, ARSALAN HAIDER ${ }^{2}$, SHOAIB LUQMAN ${ }^{3}$, ATHAR IQBAL $^{4}$, IJAZ HUSSAIN WADD ${ }^{5}$ \\ ${ }^{1}$ Associate Professor Neurology, Lahore General Hospital, Lahore \\ ${ }^{2}$ Assistant Professor Neurology, Lahore General Hospital, Lahore \\ ${ }^{3}$ Assistant Professor Neurology, Bahawalpur Victoria Hospital, Bahawalpur \\ ${ }^{4}$ Assistant Professor Neurology, Sheikh Zayed Hospital, Lahore \\ ${ }^{5}$ Associate Professor Neurosurgery, Lahore General Hospital, Lahore \\ Correspondence to: Dr. Shahid Mukhtar, Email: shahid200@hotmail.com, Cell: 03144033303
}

\begin{abstract}
Background: Obesity and migraine are the most common disorders among general population that are linked with disability and impaired life quality. Though, several studies have investigated the relationship between obesity and migraine but yet there is no complete knowledge regarding association between BMI and migraine, particularly chronic migraine.

Objective: The objective of the study was to find the association between body mass index and migraine.

Material and Methods: It was a prospective study carried out at Neurology Outpatient Department of Lahore General Hospital, Lahore. Total of 545 patients with major complaint of headache were included after fulfilling "episodic migraine" $(n=370)$ and "chronic migraine" $(n=175)$ criteria according to International Headache Society (IHS) criteria.

Results: Among 370 patients with episodic migraine (EM), 78.4\% were females while among 175 patients with chronic migraine (CM), 81.1\% were females. In EM group, the mean age of the patients was $41.72 \pm 21.35$ years and in $\mathrm{CM}$ group, it was $45.80 \pm 15.79$ years. In EM group, mean pain intensity was $4.6 \pm 2.41$ and in $\mathrm{CM}$ group, mean pain intensity was $4.3 \pm 2.51$. Among EM group patients, mean duration of headache was $4.85 \pm 5.17$ days and among CM group patients, mean duration was $20.88+8.86$ days. Mean BMI (Body Mass Index) of patients in EM groups was $22.91 \pm 3.89$ while in $\mathrm{CM}$ groups was $24.43 \pm 3.43(\mathrm{P}=0.002)$. In $\mathrm{EM}$ group, $9.7 \%$ patients and in CM group, 6.3\% patients were underweight ( $\mathrm{P}=0.189)$. In EM group, $11.4 \%$ patients and in $\mathrm{CM}$ group, $30.3 \%$ patients were overweight $(\mathrm{P}=0.002)$. However, in EM group, only $1.3 \%$ patients and in $\mathrm{CM}$ group, $3.4 \%$ patients were obese $(P=0.087)$. Multiple logistic regression analysis of chronic migraine group showed significant results $(\mathrm{P}<0.05)$ regarding headache days/month, BMI, overweight and obese.

Conclusion: Study concluded that overweight and obesity were associated factors for migraine. Chronic migraine patients were more likely to have elevated BMI than the episodic migraine patients.

Keywords: Body mass index, migraine, obesity, chronic, headache
\end{abstract}

\section{INTRODUCTION}

Headache is a prevalent complaint across the globe while migraine is one of the most frequent primary headaches. ${ }^{[1]}$ The prevalence of migraine is almost $11 \%$ among general populace and it is 7th most disabling disease in the world. ${ }^{[2]}$ As per nationwide survey, migraine one year incidence is $22.7 \%$ in Pakistan that mostly affects the people aged between 40 to 49 years. Migraine is most common disease and 3rd most significant cause of disability among people aged less than 50 years. ${ }^{[3]}$

The migraine's main symptoms comprise: headache, mostly unilateral but it can be bilateral, painful and acute, accompanied by phonophobia, photophobia, nausea and vomiting. ${ }^{[4]}$ As per number of headache days/month, migraine is categorized by IHS into: episodic migraine and chronic migraine. The EM remains for less than 15 headache days/month; and CM for 15 or more headache days/month during $>3$ months with experiencing migraine features at least eight days per month. ${ }^{[5]}$ Migraine is related to several co-morbidities such as psychiatric disorders (e.g. depression \& anxiety), cardiovascular risk factors (e.g. hypertension, diabetes, obesity \& high cholesterol level), sleep disorders, fatigue, cardiovascular and cerebrovascular diseases. ${ }^{[6]}$

A significant rise in the prevalence of overweight and obesity has been observed worldwide, ${ }^{[7]}$ being labeled a world pandemic during current years, with Pakistan ranked 9th among 188 world countries. As per WHO (World Health
Organization), since 1975 the prevalence of obesity has been increased threefold worldwide, with number of overweight people in 2016 reaching 1.9 billion. ${ }^{[8]}$ Worldwide, numerous noninfectious diseases (such as cardiovascular diseases, type-II diabetes mellitus, hypertension, dyslipidemia and carcinoma) are related to increased BMI. ${ }^{[9]}$

Particularly, general or overall body obesity, according to BMI, has been demonstrated to be associated with headache disorders in various epidemiologic and clinical studies. There is significant uncertainty regarding type of headache/obesity association and either it is specific to the migraine, or daily chronic headache, or headache generally. ${ }^{[10]}$

Both obesity and migraine are the most common disorders among general population that are linked with disability and impaired life quality. Though, several studies have investigated the relationship between obesity and migraine but yet there is no complete knowledge regarding association between BMl and migraine, particularly chronic migraine. ${ }^{[11]}$ So, the objective of this study is to find the association between body mass index and migraine in Pakistani population reporting at a Lahore General Hospital, Lahore.

\section{MATERIAL AND METHODS}

It was a prospective study, carried out at the Neurology Outpatient Department of Lahore General Hospital, Lahore. 
The target population was 18 to 65 years old patients. Pregnant females, elderly and younger people were excluded from study due to their changing weight. All patients with headache underwent fundoscopy as well as physical neurological examination. Where necessary, radiography, electroencephalography, brain CT or MRI were also carried out and patients with abnormal results were not included in the study.

During study 545 patients with major complaint of headache were included after fulfilling "Episodic Migraine $(n=370)$ " and "Chronic Migraine $(n=175)$ " criteria as per HIS criteria. Written informed consent was taken from all patients.

Pain intensity was evaluated on 11-point pain scale (no pain $=0$, mild $=1-3$, moderate $=4-6$, severe $=7-10$ ). Both weight and height of patients were measured with light clothing and with no shoes. The body mass index was calculated according to following formula: BMl=weight $(\mathrm{kg}) /$ height $(\mathrm{m})^{2}$. Using WHO guidelines, five categories were described based upon BMI: underweight $(<18.5)$, normal weight(18.5-24.9), overweight(25-29.9), obese(3034.9), and morbidly obese (35). The data of obese and morbidly obese patients was combined as one group.

Analysis was performed using SPSS version 24.0 program. Data were summarized using frequency counts and descriptive statistics. Measurement variables were expressed as means \pm SD. Multiple logistic regression analysis of chronic migraine group was also performed. A value of $p<0.05$ was considered statistically significant.

\section{RESULTS}

Table-1 exhibits that among 370 patients with episodic migraine (EM), 290 (78.4\%) were females while among 175 patients with chronic migraine (CM), 142 (81.1\%) were females. In both groups females were in majority with insignificant results $(P=0.177)$.

In EM group patients, mean age was $41.72 \pm 21.35$ years and in CM group, it was $45.80 \pm 15.79$ years. The results were found statistically significant $(P=0.002)$.

The education level of EM group patients was found better than EM group patients $(P=0.003)$.

In EM group 71 (19.1\%) patients while in CM group $49(28.0 \%)$ patients had raised blood pressure $(\mathrm{P}=0.006)$.

Result shows that among 370 patients with episodic migraine, 41 (11.1\%) were smokers and among 175 patients with chronic migraine, 26 (14.9\%) were smokers $(P=0.212)$.

In EM group, mean pain intensity was $4.6 \pm 2.41$ and in CM group, mean pain intensity was $4.3 \pm 2.51$ ( $P=0.713)$.

Similarly in EM group, mean duration of headache was $4.85 \pm 5.17$ days and in $\mathrm{CM}$ group, mean duration was $20.88+8.86$ days with significant results $(P=0.002)$.

In EM groups, 184 (49.7\%) patients and in CM group, $82(30.6 \%)$ patients had family history of headache. The results were found statistically significant $(P=0.002)$.

Among EM group patients, mean duration of headache history was $11.94 \pm 11.71$ years and in CM group patients, mean duration was $13.63 \pm 10.87$ years indicating statistically significant results $(P=0.001)$.

Table describes that mean BMI of patients in EM groups was $22.91+3.89$ while in $\mathrm{CM}$ groups mean $\mathrm{BMI}$ was $24.43 \pm 3.43(\mathrm{P}=0.002)$.
Table-2 depicts that in EM group, 36 (9.7\%) patients and in $\mathrm{CM}$ group, 11 (6.3\%) patients were underweight $(\mathrm{P}=0.189)$.

Table-1: Demographic \& clinical characteristics of episodic \& chronic migraine groups

\begin{tabular}{|c|c|c|c|}
\hline & $\begin{array}{l}\text { Episodic } \\
\text { migraine } \\
(\mathrm{n}=370) \\
\end{array}$ & $\begin{array}{l}\text { Chronic } \\
\text { migraine } \\
(\mathrm{n}=175)\end{array}$ & $\begin{array}{l}\mathrm{p}- \\
\text { value }\end{array}$ \\
\hline Female(n, \%) & $290(78.4 \%)$ & $142(81.1 \%)$ & 0.177 \\
\hline $\begin{array}{l}\text { Age (years, } \\
\text { mean } \pm S D)\end{array}$ & $41.72 \pm 21.35$ & $45.80 \pm 15.79$ & 0.002 \\
\hline $\begin{array}{l}\text { Education (n, \%) } \\
\text { Upto primary } \\
\text { Matric or inter } \\
\text { University }\end{array}$ & $\begin{array}{l}196(53.0 \%) \\
83(22.4 \%) \\
91(24.6 \%)\end{array}$ & $\begin{array}{l}131(74.8 \%) \\
32(18.3 \%) \\
12(6.9 \%)\end{array}$ & 0.003 \\
\hline Elevated BP $(n, \%)$ & $71(19.1 \%)$ & $49(28.0 \%)$ & 0.006 \\
\hline Smoking (n, \%) & $41(11.1 \%)$ & $26(14.9 \%)$ & 0.212 \\
\hline $\begin{array}{l}\text { Pain intensity } \\
\text { (mean+SD) }\end{array}$ & $4.6 \pm 2.41$ & $4.3 \pm 2.51$ & 0.713 \\
\hline $\begin{array}{l}\text { Headache days/ } \\
\text { month (mean } \pm S D \text { ) }\end{array}$ & $4.85 \pm 5.17$ & $20.88 \pm 8.86$ & 0.002 \\
\hline $\begin{array}{l}\text { Family history of } \\
\text { headache }(\mathrm{n}, \%)\end{array}$ & $184(49.7 \%)$ & $82(30.6 \%)$ & 0.285 \\
\hline $\begin{array}{l}\text { Duration of } \\
\text { headache history } \\
\text { (years, mean } \pm S D \text { ) }\end{array}$ & $11.94 \pm 11.71$ & $13.63 \pm 10.87$ & 0.001 \\
\hline $\mathrm{BMI}(\mathrm{mean} \pm \mathrm{SD})$ & $22.91 \pm 3.89$ & $24.43 \pm 3.43$ & 0.002 \\
\hline
\end{tabular}

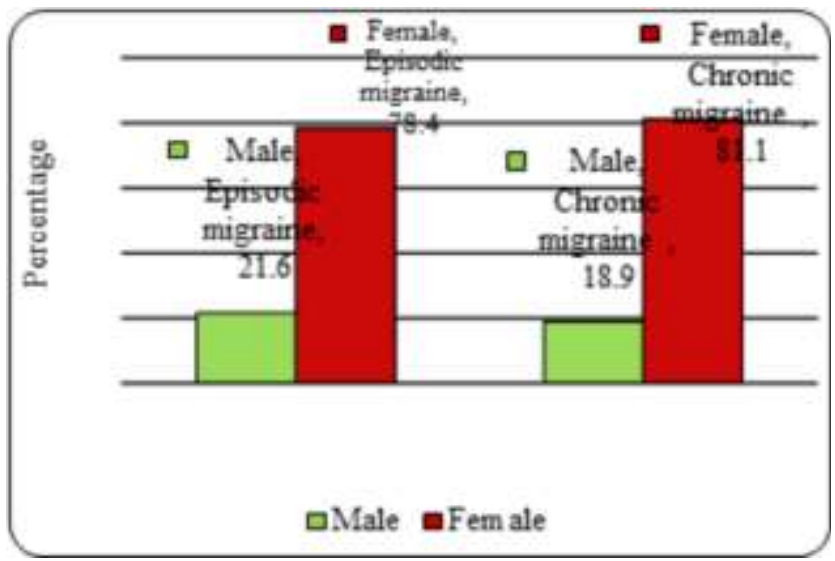

Figure-1: Frequency distribution migraine patients according to gender

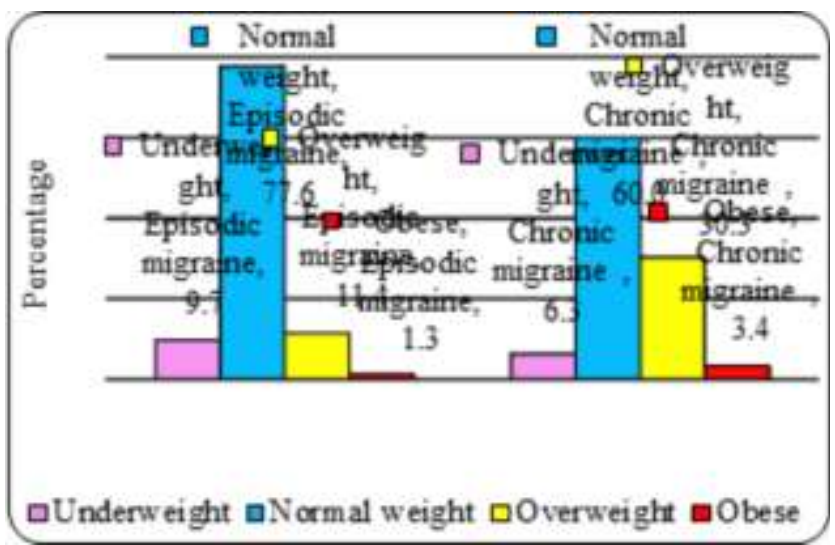

Figure-2: Frequency distribution migraine patients according to $\mathrm{BMI}$ 
In EM group, 42 (11.4\%) patients and in CM group, $53(30.3 \%)$ patients were overweight $(P=0.002)$.

However, in EM group, only 5 (1.3\%) patients and in CM group, 6 (3.4\%) patients were obese $(P=0.087)$.

Table-3 demonstrates that when multiple logistic regression analysis of chronic migraine group was carried out, significant results $(P<0.05)$ were found regarding headache days/month, BMI, overweight and obese while age, education, elevated BP, duration of headache history and underweight showed insignificant results $(P>0.05)$.

Table-2: Distribution of patients with abnormal and normal BMI in episodic and chronic migraine groups

\begin{tabular}{|l|l|l|l|}
\hline & $\begin{array}{l}\text { Episodic } \\
\text { migraine } \\
(\mathrm{n}=370)\end{array}$ & $\begin{array}{l}\text { Chronic } \\
\text { migraine } \\
(\mathrm{n}=175)\end{array}$ & $\begin{array}{l}\mathrm{p}- \\
\text { value }\end{array}$ \\
\hline Compared with normal BMl & \multicolumn{3}{|l|}{} \\
\hline Underweight & $36(9.7 \%)$ & $11(6.3 \%)$ & 0.189 \\
\hline Overweight & $42(11.4 \%)$ & $53(30.3 \%)$ & 0.002 \\
\hline Obese & $5(1.3 \%)$ & $6(3.4 \%)$ & 0.087 \\
\hline
\end{tabular}

Table-3: Multiple logistic regression analysis of chronic migraine group

\begin{tabular}{|l|l|l|l|}
\hline & $\mathrm{p}$-value & $\mathrm{OR}$ & $95 \% \mathrm{Cl}$ for OR \\
\hline Age & 0.47 & 1.03 & $0.99-1.06$ \\
\hline Education & 0.81 & 0.98 & $0.6-1.62$ \\
\hline Elevated BP & 0.77 & 0.88 & $0.32-2.36$ \\
\hline Headache days/ month & 0.002 & 1.26 & $1.22-1.34$ \\
\hline $\begin{array}{l}\text { Duration of headache } \\
\text { history }\end{array}$ & 0.56 & 0.98 & $0.96-1.02$ \\
\hline BMl & 0.004 & & \\
\hline Compared with normal weight \\
\hline Underweight & 0.689 & 0.72 & $0.13-4.15$ \\
\hline Overweight & 0.031 & 3.25 & $1.18-8.80$ \\
\hline Obese & 0.003 & 27.64 & $2.69-277.7$ \\
\hline
\end{tabular}

\section{DISCUSSION}

Migraine and obesity are the most common disorders among general population. Migraine is generally linked with abnormal body mass index, especially obesity. The migraine associated co-morbidities are psychiatric disorders (depression \& anxiety), fatigue, sleep disorder, cardiovascular risk factor (diabetes, obesity, elevated cholesterol \& hypertension) and cerebrovascular and cardiovascular diseases. Keeping in mind such issues, current study was carried out to find the association between BMI and migraine at the Neurology Outpatient Department of Lahore General Hospital, Lahore. To acquire appropriate outcomes, total 545 patients with major complaint of headache were included and divided into two groups namely Episodic Migraine (370 patients) and Chronic Migraine (175 patients).

Study revealed that most of the patients in both groups were females $(78.4 \%$ in EM group and $81.1 \%$ in $\mathrm{CM}$ group) and the result was found statistically insignificant $(P=0.177)$. The findings of our study are comparable with a study undertaken by Huang and coworkers (2018) who reported that in both groups females were in majority (77.1\% in EM group and $77.6 \%$ in CM group). ${ }^{[11]}$ Another study carried out by Huang and teammates (2019) also showed similar scenario that most of the patients in both groups were females (77.5\% in EM group and $82.7 \%$ in CM group) indicating insignificant results $(P=0.176) .{ }^{[12]}$
Age is a leading factor because with increasing age people suffer from different diseases. It was found during study that mean age of the patients in EM group was $41.72 \pm 21.35$ years while in $\mathrm{CM}$ group was $45.80 \pm 15.79$ years $(P=0.002)$. A study carried out by Huang and coworkers (2018) showed almost similar results that mean age of the patients in EM group was $40.42 \pm 2.38$ years while in $\mathrm{CM}$ group was $43.36 \pm 2.93$ years. Huang and teammates (2019) also reported in their study that mean age of the patients in EM group was $40.71+20.34$ years while in $\mathrm{CM}$ group was $46.9+16.89$ years $(P=0.001) .{ }^{[12]}$ In our study educational level was found better among EM group patients but Huang and coworkers (2018) asserted in their study that patients in $\mathrm{CM}$ group had better educational level than EM group. ${ }^{[11]}$

High blood pressure could be a major cause of migraine. It is important to mention that in EM group only $19.1 \%$ patients while in CM group $28.0 \%$ patients had raised blood pressure $(P=0.006)$. A study done by Huang and teammates (2019) also showed comparable results who confirmed that in EM group 18.9\% patients and in CM group $29.8 \%$ patients were hypertensive $(P=0.005){ }^{[12]}$ Study further disclosed that patients in both groups had severe pain. The mean pain intensity in EM group was 4.6 \pm 2.41 and in $C M$ group was $4.3 \pm 2.51(P=0.713$. Same results were reported by Huang and teammates (2019) who also elucidated that patients in both groups had severe pain (EM $4.5 \pm 2.40$ vs CM 4.4 \pm 2.62$)(P=0.714)$. ${ }^{[12] ~ S i m i l a r l y ~}$ in EM group, mean duration of headache was $4.85 \pm 5.17$ days and in $\mathrm{CM}$ group was $20.88 \pm 8.86$ days with significant results $(P=0.002)$. However, almost same findings were demonstrated by Huang and teammates (2019) that in EM group, mean duration of headache was $3.94 \pm 5.18$ days and in $\mathrm{CM}$ group was $21.79 \pm 8.95$ days $(\mathrm{P}=0.00 \overline{2}){ }^{[12]}$ Study showed very discouraging results that among EM group patients, mean duration of headache was $11.94 \pm 11.71$ years and similarly in $\mathrm{CM}$ group patients, mean duration was $13.63 \pm 10.87$ years $(P=0.001)$. Anyhow study conducted by Huang and teammates (2019) remained unable to show better scenario and reported that mean duration of headache in EM group was $10.83 \pm 10.60$ years and in $\mathrm{CM}$ group was $14.74 \pm 11.98$ years $(P=0.001){ }^{[12]}$

The people who are underweight have less chance to have migraine. The risk of migraine is increased with increasing BMI. It is significant to mention here that according to mean BMI, patients in both groups were found normal as among EM group patients mean BMl was $22.91 \pm 3.89$ while among $\mathrm{CM}$ group patients was $24.43 \pm 3.43(\mathrm{P}=0.002)$. The finding of a study carried out by Huang and teammates (2019) exhibited similar scenario who confirmed that mean BMl of patients in EM groups was $21.90 \pm 2.88$ while in $\mathrm{CM}$ groups mean $\mathrm{BMl}$ was $23.34 \pm 2.32(\mathrm{P}=0.001){ }^{[12]}$

During study patients with abnormal and normal BMI were also evaluated and found that in EM group, most of the patients $(11.4 \%)$ were overweight, followed by, underweight $(9.7 \%)$ and obese $(1.3 \%)$. Likewise in $\mathrm{CM}$ group, majority of the patients $(30.3 \%)$ were also overweight, followed by, underweight $(6.3 \%)$ and obese $(3.4 \%)$. The remaining proportion in both groups was of patients with normal BMI. Virtually the results of our study are comparable with a study conducted by Huang and 
coworkers (2018) who reported that majority of the patients in both groups were overweight (EM:15.1\% vs $\mathrm{CM}: 17.2 \%)$, followed by, underweight (EM:9.6\% vs CM:9.7\%) and obese (EM:3.0\% vs CM:3.7\%). The remaining proportion in both groups was of patients with normal BMI. ${ }^{[11]}$ Another study performed by Huang and teammates (2019) also indicated that in both groups most of the patients were overweight, followed by, underweight and obese. ${ }^{[12]}$ But the findings of a recent study undertaken by Hashmat and fellows (2019) showed that majority of the patients (33.4\%) were obese/morbidly obese, followed by overweight $(14.1 \%)$ and underweight $(11.5 \%)$ while remaining proportion was of normal patients. ${ }^{[4]}$

It is pertinent to mention here that when multiple logistic regression analysis of chronic migraine group was carried out, study found an elevated risk of having migraine among patients with headache, BMI, overweight and obesity ( $P<0.05)$. The findings of studies carried out by Thierry et al. (2018) [13] and Quach (2013) ${ }^{[14]}$ also confirmed that overweight and obesity were associated with migraine. Bigal et al. (2007) ${ }^{[15]}$, Saeed \& Shukr (2020) [16] and Adoukonou et al. (2014) ${ }^{[17]}$ reported in their studies that obesity was the leading factor for migraine. But the study carried out by Keith and associates (2008) demonstrated that obesity was associated with enhanced risk for headache, but not migraine. ${ }^{[18]}$ Similarly Özcan and Özmen (2019) [19] and Yu et al. (2012) ${ }^{[20]}$ reported no association between obesity and migraine. The findings of a study undertaken by Bigal and colleagues (2006) indicated that obesity was associated with chronic migraine. ${ }^{[21]}$ Queiroz et al. (2009) ${ }^{[22]}$ and Tellez-Zenteno et al. (2010)[23] confirmed in their study that there was insignificant association between $\mathrm{BMI}$ and migraine. The findings a similar study carried out by Huang and teammates (2019) demonstrated comparable results who reported that headache, $\mathrm{BMI}$, overweight and obesity were associated with migraine $(P<0.05) .{ }^{[12]}$

\section{CONCLUSION}

Study concluded that overweight and obesity were associated factors for migraine. Chronic migraine patients were more likely to have elevated BMI than the episodic migraine patients. Further studies are needed on large scale to find out the association between body mass index and migraine.

\section{REFERENCES}

1. Faruqi SJ, Shahbaz NN, Yahya M, Butt MA, Memon FH, Ali $S G$, et al. Prevalence of obesity in patients suffering from migraine. Int J Res Med Sci 2019; 7: 4748-52.

2. Ornello R, Ripa P, Pistoia F, Degan D, Tiseo C, Carolei A, et al. Migraine and body mass index categories: a systematic review and meta-analysis of observational studies. J Headache Pain 2015; 16: 27.

3. Jawed S, Ali W, Yaqoob U, Shah S, Uddin SMM, Haq A. Effect of migraine headache on productivity of patients according to migraine disability assessment score: a crosssectional study. Pain Ther 2019; 8: 233-8.
4. Hashmat A, Jamil H, Inam SHA, Alamgir W, Hamid S. Association between migraine and Body Mass Index in patients reporting at a military hospital, Rawalpindi. J Pak Med Assoc 2019; 69(12): 1888-90.

5. Rivera-Mancilla E, Al-Hassany L, Villalón CM, MaassenVanDenBrink A. Metabolic aspects of migraine: association with obesity and diabetes mellitus. Front Neurol 2021; 12: 686398

6. Hindiyeh NA, Zhang N, Farrar M, Banerjee P, Lombard L, Aurora SK. The role of diet and nutrition in migraine triggers and treatment: a systematic literature review. Headache 2020; 60: 1300-16.

7. Kristoffersen ES, Børte S, Hagen K, Zwart JA, Winsvold BS. Migraine, obesity and body fat distribution - a populationbased study. J Headache Pain 2020; 21: 97.

8. Butt F, Butt AF, Alam F, Aslam N, Moeed HA, Butt FA. Perception and management of obesity among Pakistani doctors. Cureus 2019; 11(2): e4156.

9. Asif M, Aslam M, Altaf S, Atif S, Majid A. Prevalence and sociodemographic factors of overweight and obesity among Pakistani adults. J Obes Metab Syndr. 2020; 29(1): 58-66.

10. Khan MM, Huda MN, Bhattacharjee M, Uddin MJ, Khan MKU. Relationship of migraine and body mass index (BMI). J Enam Med Coll 2016; 6(2): 80-7.

11. Huang $Q$, Liang $X$, Wang $S$, Mu X. Association between body mass index and migraine: a survey of adult population in China. Behavi Neurol 2018; 2018: 1-6.

12. Huang Q, Yu H, Zhang N, Guo B, Feng C, Wang S, et al. Body mass index and primary headache: a hospital-based study in China. BioMed Res Int 2019; 2019: 1-9.

13. Thierry A, Mendinatou A, Aude G, Bohr S, Dismand H. Migraine and obesity in Parakou in 2017: case-control study. Pain Stud Treatment 2018; 6: 15-23.

14. Quach P. Is there an association between body mass index and migraine headaches within the Canadian population? BMJ 2013; 8.

15. Bigal ME, Tsang A, Loder E, Serrano D, Reed ML, Lipton $\mathrm{RB}$, et al. Body mass index and episodic headaches: a population-based study. Arch Intern Med. 2007; 167(18): 1964-70.

16. Saeed AS, Shukr OMA. Migraine in obesity: is it prevalent? Diyala J Med 2020; 19(2): 1-5.

17. Adoukonou $T$, Tognon-Tchegnonsi $F$, Philomène $K$, Alabi $A$ Houinato D, Preux PM. Prevalence of migraine among university students at Parakou, Benin: a cross-sectional study. World J Neurosci 2014; 4: 18-24.

18. Keith SW, Wang C, Fontaine KR, Cowan CD, Allison DB (2008) BMI and headache among women: results from 11 epidemiologic datasets. Obesity 2008; 16: 377-83.

19. Özcan RK, Özmen SG. The association between migraine, metabolic syndrome, insulin resistance, and obesity in women: a case-control study. Med Bull Sisli Etfal Hosp 2019; 53(4): 395-402.

20. Yu S, Liu R, Yang X, Zhao G, Qiao X, Feng J, et al. Body mass index and migraine: a survey of the Chinese adult population. J Headache Pain 2012; 13: 531-6.

21. Bigal ME, Liberman JN, Lipton RB. Obesity and migraine: a population study. Neurology 2006; 66: 545-50.

22. Queiroz LP, Peres MF, Piovesan EJ, Kowacs F, Ciciarelli MC, Souza JA, et al. A nationwide population-based study of migraine in Brazil. Cephalalgia 2009; 29(6): 642-9.

23. Tellez-Zenteno JF, Pahwa DR, Hernandez-Ronquillo L, Garcia-Ramos G, Velazquez A. Association between body mass index and migraine. Eur Neurol 2010; 64(3): 134-9. 